\title{
Asociación entre la percepción de errores médicos, disminución de la calidad de vida y sintomas de depresión y desgaste profesional
}

Association between perceived medical error and worse quality of life, burnout syndrome and depressive symptoms

\begin{abstract}
Objetivo
Evaluar la frecuencia de los errores médicos (EM) percibidos como tales por los propios residentes y medir su asociación con su calidad de vida, con la presencia de síndrome de desgaste profesional o "burnout", con síntomas de depresión y con disminución de la empatía.
\end{abstract}

\section{Diseño}

Cohorte prospectiva de la Clínica Mayo (Rochester, EEUU) integrada por 184 residentes de medicina interna que comenzaron su entrenamiento durante 2003, 2004 y 2005, provenientes de 108 facultades de medicina de EEUU y de otros países.

\section{Descripción de las pruebas}

Se interrogó en forma confidencial a los residentes si estaban preocupados por algún EM mayor (sin definición estricta) que hubiesen cometido en los últimos tres meses. Los residentes que reportaban errores eran interrogados acerca de con quién lo habían comentado.

La calidad de vida fue medida a través de una escala analógica visual (LASA) que puntúa entre uno y diez y oscila entre "tan mala como es posible" y "tan buena como es posible".

El "burnout" fue medido a través del Inventario de Burnout de Maslach (en inglés $\mathrm{MBI}$ ) de 22 ítems, que evalúa tres dominios (despersonalización, agotamiento emocional y logros personales). Valores altos en despersonalización y agotamiento emocional junto con valores bajos en logros personales implican la existencia de burnout.

Para evaluar síntomas de depresión utilizaron dos preguntas: 1) durante el último mes, ¿te ha molestado en forma usual el hecho de sentirte decaído, deprimido o sin esperanza? 2)
Colin P y col. JAMA. 2006; 296:1071-1078. durante el mes pasado, ¿te ha molestado de forma usual sentir poco interés o placer en tus actividades?

La empatía se midió con el Índice de Reactividad Interpersonal (IRI). Todos estos cuestionarios son herramientas de medición validadas en una amplia variedad de condiciones médicas y poblaciones en distintos estudios.

\section{Resultados principales}

Un treinta por ciento de los participantes reportó al menos un EM mayor durante el período del estudio y haberlo discutido con colegas, supervisores o amigos y familiares cercanos.

El auto-reporte de error médico se asoció con menor calidad de vida $(p=0,02)$ y un empeoramiento en todos los dominios evaluados en el cuestionario de burnout ( $p=0,002$ para cada área). También hubo asociación positiva con la presencia de síntomas depresivos (OR 3,29; IC95\% 1,90 a 5,64) durante el período subsiguiente a haber cometido dicho error. El aumento en el burnout y la reducción en la empatía se asociaron significativamente con un aumento en la probabilidad de percibir un error durante los tres meses subsiguientes $(p<0,02$ para despersonalización, agotamiento emocional y menores logros personales, y $\mathrm{p}=0,02$ para empatía).

\section{Conclusiones}

Un tercio de los residentes reportó haber cometido algún EM en los últimos tres meses. Además del potencial efecto sobre los pacientes, la percepción de errores afectó múltiples dominios del bienestar de los médicos: disminución de la calidad de vida, aumento del burnout y síntomas de depresión.

Palabras clave: error médico, calidad de vida, burnout, empatía, depresión. Key words: medical error, quality of life, burnout, empathy, depression. Fuente de financiamiento: No referida.

\section{Comentario}

De acuerdo a Weingart y col., podría definirse EM a la falla de una acción planeada para lograr un objetivo respecto de la salud de un paciente o al empleo de un plan equivocado para alcanzarlo'. De acuerdo con Leape y col. ${ }^{2}$, los EM suelen clasificarse en diagnósticos (diagnóstico tardío o equivocado por no haber usado la prueba indicada o haberla usado mal, por haber empleado una obsoleta, o por no haber actuado ante ciertos resultados); terapéuticos (falla o demora evitable en la realización de algún procedimiento, o error en la administración de algún tratamiento por ejemplo dosis, vía de administración, elección de la droga, etc.) y preventivos (falla en administrar alguna medida profiláctica o de diagnóstico precoz).

Si bien el tema del estudio que resumimos es muy interesante por el impacto que los EM tienen en la vida cotidiana de los médicos en formación, llama la atención la metodología empleada, especialmente la relacionada al modo de definición de error médico. Sólo se utilizó el auto-reporte de errores, lo que puede generar un sesgo de clasificación*, ya que la percepción de los mismos variará de acuerdo a las distintas personalidades de los residentes. Respecto de este punto, los autores hacen hincapié en que les interesaba la autopercepción de haber cometido el error, más allá de la gravedad del mismo.

Lo más valioso de este estudio es que los cuestionarios con puntajes bajos en calidad de vida y en empatía, y altos en burnout y depresión, se asociaron a una mayor probabilidad de percibir EM en el futuro.

\section{Conclusiones de la comentadora}

Deberían hacerse esfuerzos considerables para disminuir lo más posible el número de EM y cuando estos ocurren, ofrecer a los residentes un espacio donde poder contar sus experiencias y recibir contención por parte de profesionales capacitados para este fin.

Ver glosario*

Laura Ninín [ Servicio de Medicina Familiar del Hospital Italiano de Buenos Aires. laura.ninin@ hospitalitaliano.org.ar ]

Recibido el 21/11/07 y aceptado el 20/07/08.

Ninín L. Asociación entre la percepción de errores médicos, disminución de la calidad de vida y síntomas de depresión y desgaste profesional Evid. actual. práct. ambul; 11(4):112, Jul-Ago.2008. Comentado de: Colin P. West, Mashele M. Huschka, Paul J y col. Novotny.Association of Perceived Medical Errors With Resident Distress and Empathy. A Prospective Longitudinal Study. JAMA. 2006; 296:1071-1078. Disponible en URL: http://jama.ama-assn.org/cgi/reprint/296/9/1071.pdf (último acceso 22/07/08).

\section{Referencias}

1. Weingart S y col. Epidemiology of medical error. BMJ 2000;320:774-7. Citado por: Piñero D en: La Sociedad Argentina de Cardiología frente al error médico. Revista Argentina de Cardiología. Vol 73 Nro 3 /Mayo-Junio 2005. Disponible en URL: http://www.errorenmedicina.anm.edu.ar/pdf/Carta_Pte_SAC.pdf (último acceso: 22/07/08).

2. Leape L y col. Preventing Medical Injury. Qual Rev Bull 1993;19:144-9. Citado por: Piñero D en: La Sociedad Argentina de Cardiología frente al error médico. Revista Argentina de Cardiología. Vol 73 Nro 3 /Mayo-Junio 2005. Disponible en URL: http://www.errorenmedicina.anm.edu.ar/pdf/Carta_Pte_SAC.pdf (último acceso: 22/07/08). 